\title{
New architectural design of delivery room reduces morbidity in preterm neonates: a prospective cohort study
}

\author{
Gianluca Terrin ${ }^{1 *}$, Francesca Conte ${ }^{2}$, Antonella Scipione ${ }^{1}$, Vincenzo Aleandri ${ }^{1,3}$, Maria Di Chiara ${ }^{1}$, Erica Bacchio ${ }^{1}$,
} Francesco Messina ${ }^{4}$ and Mario De Curtis $^{2}$

\begin{abstract}
Background: A multidisciplinary committee composed of a panel of experts, including a member of the American Academy of Pediatrics and American Institute of Architects, has suggested that the delivery room (DR) and the neonatal intensive care units (NICU) room should be directly interconnected. We aimed to investigate the impact of the architectural design of the DR and the NICU on neonatal outcome.

Methods: Two cohorts of preterm neonates born at $<32$ weeks of gestational age, consecutively observed during 2 years, were compared prospectively before (Cohort 1: "conventional DR") and after architectural renovation of the DR realized in accordance with specific standards (Cohort 2: "new concept of DR"). In Cohort 1, neonates were initially cared for a conventional resuscitation area, situated in the DR, and then transferred to the NICU, located on a separate floor of the same hospital. In Cohort 2 neonates were assisted at birth directly in the NICU room, which was directly connected to the DR via a pass-through door. The primary outcome of the study was morbidity, defined by the proportion of neonates with at least one complication of prematurity (i.e., late-onset sepsis, patent ductus arteriosus, intraventricular hemorrhage, periventricular leukomalacia, bronchopulmonary dysplasia, retinopathy of prematurity and necrotizing enterocolitis). Secondary outcomes were mortality and duration of hospitalization. Statistical analysis was performed using standard methods by SPSS software.
\end{abstract}

Results: We enrolled 106 neonates (56 in Cohort 1 and 50 in Cohort 2). The main clinical and demographic characteristics of the 2 cohorts were similar. Moderate hypothermia (body temperature $\leq 35.9^{\circ} \mathrm{C}$ ) was more frequent in Cohort 1 (57\%) compared with Cohort 2 (24\%, $p=0.001)$. Morbidity was increased in Cohort 1 (73 \%) compared with Cohort 2 (44 \%, $p=0.002)$. No statistically significant differences in mortality and median duration of hospitalization were observed between the 2 cohorts of the study.

Conclusions: If realized according to the proposed architectural standards, renovation of DR and NICU may represent an opportunity to reduce morbidity in preterm neonates.

Keywords: Delivery room, Neonatal intensive care unit, Resuscitation, Hypothermia, Early nasal-CPAP, Morbidity, Intraventricular hemorrhage, Patent ductus arteriosus, Sepsis

\footnotetext{
* Correspondence: gianluca.terrin@uniroma1.it

1Department of Gynecology-Obstetrics and Perinatal Medicine, "Sapienza"

University of Rome, Viale del Policlinico 155, 00161 Rome, Italy

Full list of author information is available at the end of the article
} 


\section{Background}

The American Academy of Pediatrics (AAP) and American College of Obstetricians and Gynecologists have published several editions of their Guidelines for Perinatal Care [1], and The American Institute of Architects (AIA) has similarly published their Guidelines for Construction of Hospital and Healthcare Facilities [2]. More recently, a multidisciplinary committee, consisting of a panel of experts including a member of AAP and AIA, suggested a specific architectural design of the delivery room (DR) directly connected with neonatal intensive care unit (NICU) via a pass-through door, hypothesizing an improvement in the efficiency of preterm neonate stabilization procedures [3].

Commonly, care to neonates at birth is provided in area located within the DR and, only when necessary, after initial stabilization and a brief transportation, they continue in the NICU [4]. Although this architectural organization could be acceptable for healthy term and late-preterm neonates, it may not be appropriate for critical preterm neonates [3, 5]. Resuscitation and stabilization of these subjects would require the use of advanced and expensive devices, which are preferentially located in the NICU rooms [6]. In addition, the difficult stabilization process could be complicated by handling and moving in the first minutes of life [7-9]. For these reasons, the construction of a DR directly connected via pass-through doors to the NICU appears a more appropriate strategy to meet the needs of neonates and to optimize human and economic resources. To date, no study has verified the efficacy of different architectural organization on neonatal outcomes. Starting from these considerations, we aimed to evaluate the impact of architectural DR and NICU renovation performed in accordance to predefined standards [3] on neonatal morbidity, mortality and hospitalization time.

\section{Methods}

We designed a prospective cohort study including inborn neonates, with gestational age $<32$ weeks, consecutively observed in the NICU of Evangelical Hospital "V. Betania" of Naples, Italy, from 1 January 2008 to 31 December 2009. The study was carried out in compliance with Helsinki Declaration and the ethics committee (EC) of Evangelical Hospital "V. Betania" approved it (EC number: 15233). Written informed consent was obtained from the parents of the neonates enrolled in the study. Exclusion criteria were genetic syndromes, immunodeficiency, malformations and early onset sepsis. We enrolled neonates in two cohorts according to the architectural organization of NICU and DR in which they were assisted at birth. Specifically, neonates enrolled from 1 January 2008 to 31 March 2009 were initially cared in a conventional resuscitation area situated in the DR and then transferred to the NICU, located at separate floor of the same hospital (Cohort 1: period of "conventional DR"). Starting from 1 April 2009, the NICU underwent architectural renovation in accordance with recent standards defined for neonatal DR and NICU design [3]. Thus, from 1 April to 31 December 2009 , neonates were born in a DR directly connected to NICU via a pass-through door (Cohort 2: period of "new concept of DR"). Equipment available for the initial stabilization of neonates was similar for the two cohorts of the study. In brief, self-inflating bag, T-piece resuscitator (Neopuff Infant Resuscitator, Fisher and Paykel, New Zealand), pulse-oximeter, humidifier, and oxygen blender were available for both cohorts of the study. Resuscitation was initially performed with an oxygen concentration $\leq$ $30 \%$ and then titrated to maintain target saturation. Polyethylene plastic wrap was routinely used for babies delivered at less than 29 weeks gestation to avoid hypothermia. In the first period of the study (Cohort 1) after initial stabilization in the DR, neonates were transferred to the NICU by a neonatal incubator provided with a mechanical ventilator, without infant-flow system and heated and humidified gas. During the second study period (Cohort 2), respiratory support by invasive mechanical ventilation or by nasal continuous positive airway pressure (n-CPAP) with infant-flow system and heated and humidified gas, was started immediately after birth when appropriate, and it was not discontinued or modified if not specifically indicated by clinical needs. In NICU, standard care was applied in a similar manner, in both periods of the study, from recovery to discharge, according to our policies.

\section{Endpoint}

The main endpoint was morbidity, defined by the proportion of neonates presenting at least one of the main complications of prematurity reported below: late-onset sepsis (LOS) [10, hemodynamically significant patent ductus arteriosus (PDA) [11], intraventricular hemorrhage (IVH) [12], periventricular leukomalacia (PVL) [13], bronchopulmonary dysplasia (BPD) [14], retinopathy of prematurity (ROP) [15], and necrotizing enterocolitis (NEC) [16]. We also compared the mortality rates and duration of hospitalization in the two cohorts of the study.

\section{Data collection}

Clinical data regarding: birth weight, gestational age at birth, mode of delivery, multiple birth, sex, Apgar score at 1 and $5 \mathrm{~min}$, antenatal corticosteroid treatment, indication for preterm delivery, characteristics of resuscitation interventions at birth, body temperature within the first $60 \mathrm{~min}$ of life, administration of exogenous surfactant, occurrence of LOS, PDA, IVH, PVL, BPD, ROP, and NEC were collected by researchers unaware of the study aims and design. Diagnosis of LOS, PDA, IVH, 
PVL, BPD, ROP, and NEC were performed according to previously used criteria [10-16]. Data on duration of hospital stay and mortality were also collected and analyzed.

\section{Statistics}

To demonstrate a $20 \%$ of reduction in morbidity between the two cohorts of the study with $80 \%$ power and type error $=0.05$ (2-tailed test), a minimum sample size of 50 neonates for each group was required. The KolmogorovSmirnov test was used to determine whether variables were normally distributed. For continuous variables, groups were compared by using the $t$ test of equality of means, the Mann-Whitney $U$ test, and the Kruskal-Wallis test. The chi-square test and Fisher's exact test were used for categorical variables. We performed a multivariate analysis using binary logistic regression analysis to evaluate whether morbidity was influenced by confounding variables (i.e., gestational age, birth weight, mode of delivery, multiple birth, sex, antenatal corticosteroid treatment, Apgar score at $5 \mathrm{~min}$, and study cohort assignment). The level of significance for all statistical tests was 2sided $(p<0.05)$. Statistical analysis was performed by a statistician blinded to patient group assignment, using SPSS version 19.0 for Windows (SPSSInc).

\section{Results}

We enrolled 106 neonates, 56 in Cohort 1 and 50 in Cohort 2. Main clinical and demographic characteristics of the two cohorts were similar, as reported in Table 1.

Morbidity was increased in Cohort 1 compared with Cohort 2 (Fig. 1). In particular, the rate of neonates presenting LOS, PDA and IVH ( $\geq$ II grade) was significantly increased in Cohort 1 compared with Cohort 2 (Table 2). Occurrence of moderate hypothermia defined as body temperature $\leq 35.9^{\circ} \mathrm{C}$ [17] within the first $60 \mathrm{~min}$ of life

Table 1 Main clinical characteristics and resuscitation interventions at birth of study population

\begin{tabular}{|c|c|c|c|}
\hline & $\begin{array}{l}\text { Cohort } 1 \\
\text { (conventional delivery room) }^{\mathrm{a}}\end{array}$ & $\begin{array}{l}\text { Cohort } 2 \\
\text { (new concept of delivery room) })^{a, b}\end{array}$ & $p$ \\
\hline Number of neonates & 56 & 50 & - \\
\hline \multicolumn{4}{|l|}{ Clinical characteristics } \\
\hline Body birth weight, $g$ & $1114 \pm 285$ & $1033 \pm 315$ & 0.066 \\
\hline Gestational age, w & $28 \pm 0.3$ & $28 \pm 0.5$ & 0.480 \\
\hline Caesarean section, n (\%) & $50(89)$ & $46(92)$ & 0.746 \\
\hline Twins, n (\%) & $14(25)$ & $18(36)$ & 0.192 \\
\hline Male, n (\%) & $29(52)$ & $22(44)$ & 0.423 \\
\hline Apgar at $1 \mathrm{~min}$ & $5 \pm 0.2$ & $5 \pm 0.1$ & 0.850 \\
\hline Apgar at 5 min & $7 \pm 0.1$ & $7 \pm 0.2$ & 0.430 \\
\hline Prenatal corticosteroids, n (\%) & $32(58)$ & $22(44)$ & 0.146 \\
\hline Surfactant therapy, n (\%) & $40(71)$ & $42(84)$ & 0.123 \\
\hline \multicolumn{4}{|l|}{ Indications for preterm delivery } \\
\hline Spontaneous preterm labour & 40 & 37 & 0.767 \\
\hline Preterm premature rupture of membranes & 8 & 6 & 0.422 \\
\hline Hypertensive disorders of pregnancy & 6 & 5 & 0.904 \\
\hline Intrauterine growth restriction & 2 & 2 & 0.908 \\
\hline \multicolumn{4}{|l|}{ Resuscitation interventions at birth } \\
\hline Oxygen therapy, n (\%) & $53(95)$ & $45(90)$ & 0.471 \\
\hline Positive pressure ventilation with face mask, n (\%) & $23(41)$ & $25(50)$ & 0.357 \\
\hline Intubation, n (\%) & $34(61)$ & $29(58)$ & 0.776 \\
\hline Drug administration, n (\%) & $1(2)$ & $2(4)$ & 0.610 \\
\hline Chest compression, n (\%) & $4(7)$ & $2(4)$ & 0.679 \\
\hline Nasal-CPAP in delivery room & $10(17.9)$ & $9(18.0)$ & 0.985 \\
\hline Nasal-CPAP without interruption during the first $30^{\prime}$ after birth ${ }^{c}$ & $0(0.0)$ & $9(18)$ & 0.001 \\
\hline
\end{tabular}

${ }^{a}$ Data expressed as mean \pm standard deviation, when not specified

bDR directly connected to the NICU according to architectural standards, as described in the text.

I In the Cohort 1 nasal-CPAP administered by infant-flow system with heated and humidified gas, started in delivery room, was discontinued during transportation from point of delivery to the neonatal intensive care unit (NICU) located at different floor of the same Hospital. During the transportation to the NICU, neonates in the Cohort 1, were ventilated with nasal-CPAP without infant-flow system, heated and humidified gas 


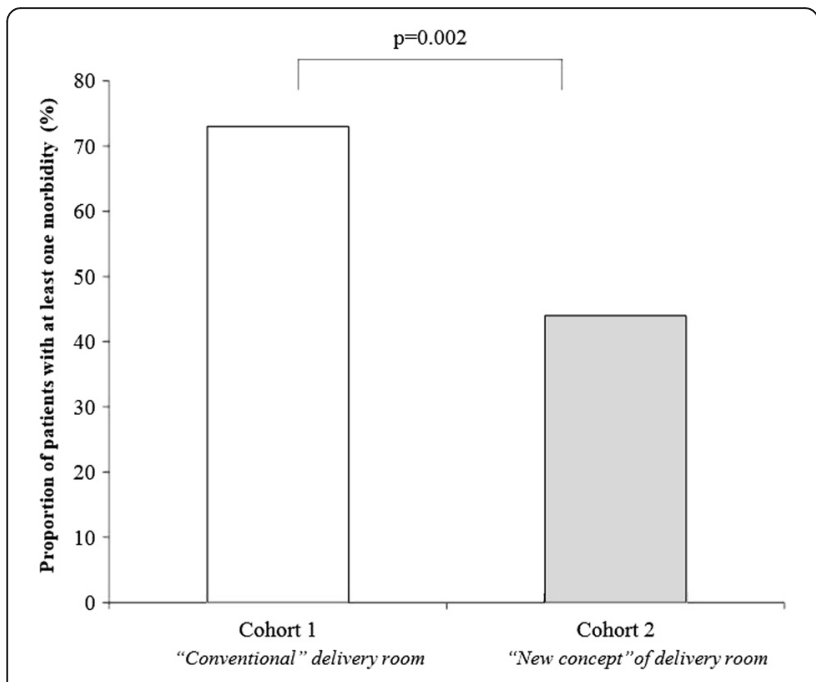

Fig. 1 Influence of Architectural design of delivery room on morbidity

was more prevalent in Cohort 1 (57.1\%) compared with Cohort $2(24.0 \%, p=0.001)$.

The use of non-invasive ventilation without interruption during the first $30 \mathrm{~min}$ of life was higher for neonates included in Cohort 2 (Table 2). No difference in mortality rate was observed between the two study cohorts (14.3\% in Cohort 1 vs $10.0 \%$ in Cohort 2, $p=0.502$ ). The median duration of hospitalization for survivals was similar in the two study cohorts (51 days, interquartile range 36 , in Cohort 1 vs. 53 days, interquartile range 34, in Cohort $2, p=0.541$ ). A multivariate analysis demonstrated that morbidity was associated with body birth weight and by cohort assignment (Table 3).

\section{Discussion}

The main goal of the architectural organization of a DR is to facilitate the transition of the fetus to the extrauterine life [18]. Hospitals vary in their approach to the details of how to prepare the resuscitation area for neonates at birth. Some hospitals have an area of the DR equipped for neonatal resuscitation not in direct communication with the NICU, whereas others have the DR adjacent to the NICU, allowing assistance of critical neonates directly in the environment of the intensive care unit $[4,18]$. Previous studies analyzed how different clinical practices at birth may influence preterm neonatal health [18]. However, the impact of different architectural designs of DR on clinical outcomes had not been previously verified. Recent data showed that up to $80 \%$ of delivery services resuscitate newborns in the DR, while less than $8 \%$ admit infants directly into a resuscitation bed in NICU adjacent to DR [4]. We demonstrated that the last option may have significant advantages for preterm neonates. Optimization of assistance in the first minutes of life would help to improve transition from fetal to neonatal life, reducing the risk of destabilization, particularly in preterm neonates [6]. However, recommendations for resuscitation of preterm neonates at birth are not respected in many points [4, 19-21]. Discrepancies between recommendations and clinical practice may depend, at least in part, on the inadequacy of areas dedicated to resuscitation at birth [4, 19-23]. It has been suggested that the incorporation of an intensive care environment into the DR could promote the application of adequate resuscitation practice at birth, potentially leading to a reduction of early and long-term complications of

Table 2 Main outcomes of study population

\begin{tabular}{|c|c|c|c|}
\hline & Cohort 1 (conventional DR) & Cohort 2 (new concept of DR ${ }^{a}$ ) & $\mathrm{p}$ \\
\hline Number of neonates & 56 & 50 & - \\
\hline \multicolumn{4}{|l|}{ Outcomes } \\
\hline Late-onset sepsis, n (\%) & $10(18)$ & $1(2)$ & 0.008 \\
\hline Late-onset culture-proven sepsis, n (\%) & $7(12.5)$ & $1(2.0)$ & 0.043 \\
\hline Patent ductus arteriosus ${ }^{\mathrm{b}}, \mathrm{n}(\%)$ & $26(46)$ & $13(26)$ & 0.029 \\
\hline Intraventricular hemorrhage, n (\%) & $19(34)$ & $6(12)$ & 0.008 \\
\hline Intraventricular hemorrhage $\geq \|$ grade, n (\%) & $9(16)$ & $2(4)$ & 0.042 \\
\hline Intraventricular hemorrhage $\geq$ III grade, n (\%) & $3(5.4)$ & $2(4.0)$ & 0.554 \\
\hline Periventricular leukomalacia, n (\%) & $2(4)$ & $3(6)$ & 0.556 \\
\hline Necrotizing enterocolitis, n (\%) & $1(2)$ & $3(6)$ & 0.341 \\
\hline Bronchopulmonary dysplasiac, n (\%) & $9(19)$ & $7(15)$ & 0.649 \\
\hline Retinopathy of prematurity, n (\%) & $7(12)$ & $6(12)$ & 0.938 \\
\hline Exitus, n (\%) & $8(14)$ & $5(10)$ & 0.502 \\
\hline
\end{tabular}

${ }^{a}$ DR directly connected to the NICU according to architectural standards, as described in the text.

${ }^{b}$ Hemodynamically-significant patent ductus arteriosus requiring a pharmacologic treatment, as described in the text.

${ }^{\mathrm{C}}$ Defined as need of oxygen therapy at 36 weeks of post-conceptional age 
Table 3 Multivariate analysis evaluating the influence of different variables on morbidity

\begin{tabular}{llll}
\hline Variables & B & Odds ratio $(95 \%$ confidence interval $)$ & $p$ \\
\hline Birth weight & -0.002 & $0.998(0.996-1.000)$ & 0.023 \\
Architectural design of DR & 0.003 \\
Prenatal corticosteroids & -1.457 & $0.233(0.089-0.609)$ & 0.002 \\
Twin pregnancy & -0.336 & $0.714(0.280-1.825)$ & 0.805 \\
Cesarean section & 0.128 & $1.136(0.412-3.138)$ & 1.000 \\
$5^{\prime}$ Apgar score & -0.000 & $1.000(0.154-6.478)$ & 0.306 \\
\hline
\end{tabular}

${ }^{a}$ new architectural design reduce risk of morbidity in a multivariate analysis constant 5372

prematurity $[6,9]$. If this organization is desirable, the realization of the resuscitation area in duplicate (i.e. in DR and in NICU) in the same hospital is expensive in terms of both economic and human resources. In addition, it has been widely reported that morbidity and mortality rates are increased for the most immature neonates who require transportation [24-26]. Our results suggest that even brief transportations from DR to NICU between different points of the same hospital may have negative consequences on neonatal outcomes. On the basis of these considerations, a DR in direct communication with the NICU probably represents the most appropriate architectural solution [3].

The positive effects observed in neonates receiving the first care directly in the NICU may have multiple explanations. Firstly, the reduction of the risk of hypothermia, considered a crucial aspect of resuscitation at birth [27]. Despite advances in techniques adopted to maintain the newborn infant's temperature within the normal range during stabilization (i.e., radiant warmers, heated mattress, polyethylene bag and/or cap, increasing the DR temperature), a significant rate of hypothermia was frequently reported [28-33]. The neonates who require transportation during the first minute of life often cross into and out of multiple different environments, with wide temperature and humidity variations and consequent increased risk of hypoxemia and increased pulmonary resistance [8]. Hypothermia and re-warming have been also associated with increased activity of prostaglandin-synthase and nitric oxide synthase, that are crucial mediators in the pathogenesis of this complication of prematurity, including persistence of ductus arteriosus $[34,35]$. In a large observational study, up to $46 \%$ of very low birth weight (VLBW) neonates were moderately hypothermic at admission in NICU [29]. Laptook et al. also demonstrated that the admission temperature was inversely related to mortality and LOS rate, with $28 \%$ increase in mortality and $11 \%$ increase in LOS per $1{ }^{\circ} \mathrm{C}$ of decrease in body temperature [29]. Similarly, Miller et al. found that mild and moderate hypothermia were very common among VLBW neonates admitted in NICU and they revealed a positive association between moderate hypothermia and adverse neonatal outcomes [33]. Accordingly, we confirmed that maintenance of optimal body temperature is essential to reduce hypothermia and related morbidities [29, 33, 36]. For the first time, we have demonstrated that this objective may be facilitated when neonates are assisted directly in a NICU at birth [3, 37].

The early use of n-CPAP at birth has been recommended by recent guidelines in order to promote alveolar recruitment [38-40]. At the same time, alveolar de-recruitment may have a negative impact on neonatal stabilization [41, 42]. In Cohort 2 the n-CPAP was administered by using an infant-flow system, heated and humidified gas, without any interruption during stabilization period, and thus without risk of alveolar de- recruitment $[41,42]$. In Cohort 1 , the use of infantflow n-CPAP system and of heated and umidified gas was interrupted during transportation from the point of delivery to the NICU. We speculate that this interruption may have determined alveolar de-recruitment and additional loss of body temperature and possible increase in pulmonary resistance [36, 41, 42].

Although interesting, the results of this study should be interpreted considering its limitations. The study has a non-randomized design. However, for obvious ethical reasons it is difficult to address the aim of the research with a different study design. The high rate of LOS and of IVH observed in the Cohort 1 may depend on the small number of the patients enrolled in each study period. Thus, the differences in these outcomes between the two cohorts, despite their statistical significance, should be interpreted with caution, because they may be coincidental rather than dependent on architectural renovation. Finally, the limited use of prenatal steroids may have influenced final neonatal outcomes. These results may be secondary to the high number of mothers not receiving adequate prenatal care and who were directed to the birth-Hospital only when preterm delivery was imminent. However, the use of prenatal steroids was similar between the two cohorts of the study.

\section{Conclusions}

Architectural renovation of DR may represent an opportunity to improve the outcome of preterm babies, if performed according to specific standards [3]. Despite 
the necessity of further evidence, this study provides useful information for planning architectural organization of the DR. The optimization of human and instrumental resources obtained with this kind of intervention merits further research.

\section{Abbreviations}

BPD: bronchopulmonary dysplasia; DR: delivery room; IVH: intraventricular hemorrhage; LOS: late onset 1 sepsis; n-CPAP: nasal continuous positive airway pressure; NEC: necrotizing enterocolitis; NICU: neonatal intensive care unit; PDA: patent ductus arteriosus; PVL: periventricular leukomalacia; ROP: retinopathy of prematurity; VLBW: very low birth weight.

\section{Competing interests}

The authors declare that they have no competing interests.

\section{Authors' contributions}

GT, FC and FM designed research; GT performed data monitoring and statistical analysis; FC, AS, EB MDiC and MDeC cared for the patients, and analyzed critically collected data; GT, VA and $\mathrm{MDeC}$ revised the final version of the paper. Finally, all the authors read and approved the final manuscript.

\section{Acknowledgements}

None

\section{Author details}

'Department of Gynecology-Obstetrics and Perinatal Medicine, "Sapienza" University of Rome, Viale del Policlinico 155, 00161 Rome, Italy. Department of Pediatrics, "Sapienza" University of Rome, Viale del Policlinico 155, Rome 00161, Italy. ${ }^{3}$ Research Center on Evaluation of Quality in Medicine CEQUAM, "Sapienza" University of Rome, Rome, Italy. ${ }^{4}$ Department of Perinatal Medicine, Evangelical Hospital "V. Betania", Via Argine 604, Naples 80147, Italy.

Received: 23 January 2015 Accepted: 16 March 2016

Published online: 23 March 2016

\section{References}

1. American Academy of Pediatrics/American College of Obstetricians and Gynecologists: Guidelines for Perinatal Care. 6th edn. Elk Grove Village: IL/Washington, DC, 2007.

2. The American Institute of Architects Academy of Architecture for Health Guidelines for Design and Construction of Hospital and Health Care Facilities. Washington: The American Institute of Architects Academy of Architecture for Health; 2006.

3. White RD. Recommended standards for the newborn ICU. J Perinatol. 2007:27:S4-19.

4. Leone TA, Rich W, Finer NN. A survey of delivery room resuscitation practices in the United States. Pediatrics. 2006:117:164-75.

5. Rich WD, Leone T, Finer NN. Delivery room intervention: improving the outcome. Clin Perinatol. 2010;37(1):189-202.

6. Vento M, Aguar M, Leone TA, Finer NN, Gimeno A, Rich W, Escrig R, Brugada M. Using Intensive Care Technology in the Delivery Room. A New Concept for the Resuscitation of Extremely Preterm Neonates. Pediatrics. 2008;122(5):1113-6.

7. Vandenberg KA. Individualized developmental care for high risk newborns in the NICU: A practice guideline. Early Hum Dev. 2007;83(7):433-42.

8. Woodward GA, Kirsch R, Stone Trautman M, Kleinman ME, Wernovsky G, Marino BS. Stabilization and transport of the high-risk infant. In: Gleason CA, Devaskar SU, editors. Avery's Diseases of the Newborn. 9th ed. Philadelphia: Elsevier; 2012. p. 341-56

9. Finer NN, Rich W, Halamek LP, Leone TA. The delivery room of the future: the fetal and neonatal resuscitation and transition suite. Clin Perinatol. 2012;39(4):931-9.

10. Terrin G, Passariello A, Manguso F, Salvia G, Rapacciuolo L, Messina F, et al. Serum calprotectin: An antimicrobial peptide as a new marker for the diagnosis of sepsis in very low birth weight newborns. Clin Dev Immunol. 2011;2011:291085

11. Terrin G, Conte F, Oncel MY, Scipione A, McNamara PJ, Simons S, et al. Paracetamol for the treatment of patent ductus arteriosus in preterm neonates: a systematic review and meta- analysis. Arch Dis Child Fetal Neonatal Ed 2015, fetalneonatal-2014-307312

12. Papile LA, Burstein J, Burstein R, Koffler H. Incidence and evolution of subependymal and intraventricular hemorrage: a study of infants with birth weight less than $1500 \mathrm{gm}$. J Pediatr. 1978;92(4):529-34.

13. Chao CP, Zaleski CG, Patton AC. Neonatal hypoxic-ischemic encephalopathy: multimodality imaging findings. Radiographics. 2006;26(1):S159-72

14. Bancalari E. Changes in the pathogenesis and prevention of chronic lung disease of prematurity. Am J Perinatol. 2001;18:1-9.

15. International Committee for the Classification of Retinopathy of Prematurity. The International Classification of Retinopathy of Prematurity Revisited. Arch Ophtalmol. 2005:123(7):991-9.

16. Terrin G, Passariello A, Canani RB, Manguso F, Paludetto R, Cascioli C. Minimal enteral feeding reduces the risk of sepsis in feed-intolerant very low birth weight newborns. Acta Paediatr. 2009;98(1):31-5.

17. Soll RF. Heat loss prevention in neonates. J Perinatol. 2008; Suppl 1:S57-9.

18. Leone TA, Finer NN. Resuscitation in the Delivery Room. In: Gleason CA, Devaskar SU, editors. Avery's Diseases of the Newborn. 9th ed. Philadelphia: Elsevier; 2012.

19. Mitchell A, Niday P, Boulton J, Chance G, Dulberq C. A prospective clinical audit of neonatal resuscitation practices in Canada. Adv Neonatal Care. 2002;2(6):316-26.

20. El-Naggar W, McNamara PJ. Delivery room resuscitation of preterm infants in Canada current practice and views of neonatologists at level III centers. J Perinatol. 2012:32:491-7.

21. Mann C, Ward C, Grubb M, Hayes-Gill B, Crowe J, Marlow N, Sharkey D. Marked variation in newborn resuscitation practice: a national survey in the UK. Resuscitation. 2012;83(5):607-11.

22. Phibbs CS, Baker LC, Caughey AB, Danielsen B, Schmitt SK, Phibbs RH Level and volume of neonatal intensive care and mortality in very low-birth-weight infants. N Engl J Med. 2007:356(21):2165-75.

23. Tracy M, Downe L, Holberton J. How safe is intermittent positive pressure ventilation in preterm babies ventilated from delivery to newborn intensive care unit? Arch Dis Child Fetal Neonatal Ed. 2004;89(1):F84-7.

24. Lee SK, McMillan DD, Ohlsson A, Boulton J, Lee DS, Ting S, Liston R. The benefit of preterm birth at tertiary care centers is related to gestational age. Am J Obstet Gynecol. 2003;188(3):617-22.

25. Mohamed MA, Aly H. Transport of premature infants is associated with increased risk for intraventricular haemorrhage. Arch Dis Child Fetal Neonatal Ed. 2010;95(6):F403-7.

26. Thorp JA, Jones PG, Clark RH, Knox E, Peabody JL. Perinatal factors associated with severe intracranial hemorrhage. Am J Obstet Gynecol. 2001;185(4):859-62.

27. Chitty $\mathrm{H}$, Wyllie J. Importance of maintaining the newly born temperature in the normal range from delivery to admission. Semin Fetal Neonatal Med. 2013:18(6):362-8.

28. Costeloe K, Hennessy EM, Haider S, Stacey F, Marlow N, Draper ES. Short term outcomes after extreme preterm birth in England: comparison of two birth cohorts in 1995 and 2006 (the EPlcure studies). BMJ. 2012;345:e7976e89.

29. Laptook AR, Salhab W, Bhaskar B. Admission temperature of low birth weight infants: predictors and associated morbidities. Pediatrics. 2007;119:e643e9.

30. Ogunlesi TA, Ogunfowora OB, Adekanmbi FA, Fetuga BM, Olanrewaju DM. Point-of-admission hypothermia among high-risk Nigerian newborns. BMC Pediatr. 2008:8:40

31. Mullany LC, Katz J, Khatry SK, LeClerq SC, Darmstadt GL, Tielsch JM. Risk of mortality associated with neonatal hypothermia in southern Nepal. Arch Pediatr Adolesc Med. 2010;64(7):650e6.

32. de Almeida MF, Guinsburg R, Sancho GA, Rosa IR, Lamy ZC, Martinez FE, da Silva RP, Ferrari LS, de Souza Rugolo LM, Abdallah VO, Silveira Rde C. Brazilian Network on Neonatal Research: Hypothermia and early neonatal mortality in preterm infants. J Pediatr. 2014:164(2):271-5.

33. Miller SS, Lee HC, Gould JB. Hypothermia in very low birth weight infants: distribution, risk factors and outcomes. J Perinatol. 2011:31 Suppl 1:49-56.

34. Clyman RI. Patent ductus arteriosus in the preterm infant. In: Gleason CA, Devaskar SU, editors. Avery's Diseases of the Newborn. 9th ed. Philadelphia: Elsevier; 2012. p. 751-61.

35. Evora PR, Cable DG, Chua YL, Rodrigues AJ, Pearson PJ, Schaff HV. Nitric oxide and prostacyclin-dependent pathways involvement on in vitro induced hypothermia. Cryobiology. 2007;54(1):106-13. 
36. te Pas AB, Lopriore E, Dito I, Morley CJ, Walther FJ. Humidified and heated air during stabilization at birth improves temperature in preterm infants. Pediatrics. 2010;125(6)::1427-32.

37. Bhatt DR, White R, Martin G, Van Marter $\sqcup$, Finer N, Goldsmith JP, Ramos $C$ Kukreja S, Ramanathan R. Transitional hypothermia in preterm newborns. J Perinatol. 2007;27 Suppl 2:S45-7.

38. Schmölzer GM, Kumar M, Pichler G, Aziz K, O'Reilly M, Cheung PY. Non-invasive versus invasive respiratory support in preterm infants at birth: systematic review and meta-analysis. BMJ. 2013;347:f5980.

39. Sweet DG, Carnielli V, Greisen G, Hallman M, Ozek E, Plavka R, Saugstad OD, Simeoni U, Speer CP, Vento M, Halliday HL. European Association of Perinatal Medicine: European consensus guidelines on the management of neonatal respiratory distress syndrome in preterm infants- 2013 update. Neonatology. 2013;103(4):353-68.

40. Committee on Fetus and Newborn; American Academy of Pediatrics. Respiratory support in preterm infants at birth. Pediatrics. 2014;133(1):171-4.

41. Schmolzer GM, Te Pas AB, Davis PG, Morley CJ. Reducing lung injury during neonatal resuscitation of preterm infants. J Pediatr. 2008;153:741-5.

42. Lachmann B. Open up the lung and keep the lung open. Intensive Care Med. 1992;18:319-21.

Submit your next manuscript to BioMed Central and we will help you at every step:

- We accept pre-submission inquiries

- Our selector tool helps you to find the most relevant journal

- We provide round the clock customer support

- Convenient online submission

- Thorough peer review

- Inclusion in PubMed and all major indexing services

- Maximum visibility for your research

Submit your manuscript at www.biomedcentral.com/submit
Biomed Central 